\title{
George Z. F. Bereday (Zygmunt Fijałkowski) and his comparative method in educational research
}

\author{
Justyna Wojniak \\ Pedagogical University of Krakow, Podchorążych 2, 30-084 Kraków, Poland
}

\begin{abstract}
The paper concerns George Bereday's (Zygmunt Fijałkowski 1920-1983) scientific activities and his contribution to the development of comparative education as a scientific discipline. Bereday was a researcher of Polish origin and a professor of Columbia University. His works concern methodological aspects of comparative research in education, and his key study is entitled Comparative Method in Education. The main assumption of this method is to analyze educational facts in a broad social and political context. Bereday also examined the education system and policy in the Soviet Union, as well as in the United States and Japan. An important issue of his interest was mass education, including that on a university level, from the point of view of American and European experiences.
\end{abstract}

Keywords: comparative education, comparative method, political geography

\section{Introduction - Bereday's life and scientific career}

George Bereday (Zygmunt Fijałkowski - 1920-1983) was a researcher of Polish origin and a professor of Columbia University. Despite his unquestionable contribution to the development of comparative education as a scientific discipline, both Bereday himself and his achievements remain insufficiently recognized in science of education worldwide. Also in Poland, his native country, his works were not analyzed too deeply due to the lack of their translations. The basic information available is limited to short references, thus the topic remains unknown even on the Polish ground.

The information on Bereday's personal life is scarce. The data available in the archives of Columbia University is rather brief and limited to a few facts [1]. In his Curriculum Vitae of 1978, Bereday provided some information on his birth date and place, which is July 15th 1920, Warsaw (Poland), and he described his personal situation: married to Mary Hale Gillam of Minneapolis, father of three children: Mariko (Japanese-American), Cornelia Krystyna and Thaddeus Matthew Sigmund. The Curriculum Vitae also includes the information on Bereday's military service: during the World War II he served in the Polish Cavalry and the British Parachute Regiment. He was awarded the War Order of Virtuti Militari, Poland's highest military decoration, for his contribution as a parachute

\footnotetext{
${ }^{1}$ Corresponding author: justyna.wojniak@up.krakow.pl
} 
battalion commander in the Arnhem Airborne Operation in Holland [2] (Comparative Education, 1984, p. 5).

After the World War II, he decided to stay abroad, first in the UK, and then he moved to the US. There is a need for a more detailed insight to Bereday's life in order to reconstruct the circumstances of his decision on the immigration, as well as his earlier life - family background in the context of pre-war situation in Poland. It is an important part of the research, especially from the perspective of his individual access to education, which was quite limited in Poland of that time, and Bereday's choice of his university faculties, as well as in terms of his further standpoint on the matter of public education, its inclusion and availability not only for the elite [3].

As for Bereday's educational background, his comprehensive education and studies in a number of disciplines such as economics, sociology, history, political science and law are worth emphasizing. Bereday held bachelor's and master's degrees from few higher education institutions: London University (economics and sociology, 1940-1944, B.Sc.), Oxford University (history, political science, 1947-1950, B.A., 1953 M.A.), Harvard University (sociology, comparative education, 1950-1953, M.A.), and Columbia University (Law, 1976, J.D.) (Bereday, 1978). He was developing his academic career from 1955 at Teachers College of Columbia University. Furthermore, he cooperated with Moscow University (1961), Tokyo University (1962), or University of Hawaii (1969-1970), and many others as Warsaw, Edinburgh, Heidelberg, Barcelona, Paris, Stockholm, Singapore, Kuala Lumpur, playing a role of an exchange or visiting professor. Besides his scientific and didactic activities, Bereday was also involved in political and diplomatic work in the field of culture education. He was a member of cultural missions to USSR (1958), representing the US Department of Education, and to Finland (1966), representing the US Department of State. In 1969, he was appointed by the US Department of State as a member of delegation to the US-Japan Cultural Conference, and in 1970 he was nominated a chief of the US Department of State Short Term American Grantee Mission to Western Europe. His expertise in the field of education was of great value also for some international organizations - between 1970-1971, Bereday served as a consultant for the Organization for Economic Cooperation and Development in Paris, and in 1971, also in Paris, he held a function of a principal consultant and an editor of the United Nations Feasibility Study for UNESCO.

Bereday was a founding editor of the "Comparative Education Review" and a joint editor of the "Year Book of Worlds Education" for numerous years. His books and articles were published in eight languages, as he was proficient in Polish (native), English, French, German, Russian, Italian, Spanish and Japanese. In his research, Bereday specialized in studies of the Soviet Union education policy, as well as American, Japanese and Western Europe education systems and their social and political context [4].

\section{The purpose of comparative research in education}

Although Bereday's key topic of interest was comparison of education practices and experiences of various nations, he should not be viewed as a "founding father" of the comparative education phenomenon. One must take into consideration that the origins of such investigations date back to the first half of 19th century, and the first researcher who explored this field was Marc Antoine Jullien de Paris, whose work entitled Esquisse et vues préliminaires d'un ouvrage sur l'éducation comparée, et séries de questions sur l'éducation of 1817, has been viewed as the "field's originating source" [5].

Development of comparative studies and a comparative method in education research might be divided into three phases, as Bereday described it [6]. The first phase was called a period of "borrowing" related to Marc Antoine Jullien de Paris, and it included collecting 
and cataloguing descriptive educational data. The best practices of one country were gathered in order to transplant them to others. The aim was to follow the systems which were considered effective, and to develop or improve those which were recognized as underdeveloped or imperfect. Bereday mentioned Domingo Sarmiento in Argentina or Horace Mann in America, who studied foreign education systems and expressed their strong belief that their countries should borrow the best practices from other states, namely the West European nations. It was also a typical practice of French and British empires in Africa, India etc., and a part of their general policy during the colonial period, when the mother country attempted to extend and to retain its control over a particular territory, exercising its own political and social practices.

The second period - of "prediction" - was founded by Michael Sadler and a series of his Special Reports on Educational Subjects of 1897-1902 and reports of 1903-1906, developed for local British education authorities for the purpose of reorganization their educational regulations after the Education Act 1902. In this case, the preparatory process before the transplantation was emphasized. The borrowing was not automated, as Sadler advised taking into account the principles which a particular nation is attached to and which determine effectiveness of an education system in a given country. Mistakes and achievements of other countries may only pose an example, and their experiences were never completely identical. What is important is the fact that Sadler's successors Friedrich Schneider, Nicolas Hans or Pedro Roselló - paid their attention to the foundations of education - the social causes behind the pedagogical scene [7].

The third phase was described as a period of "analysis" and linked to Isaac Kandel and his Comparative Education. In his view, "The factors and forces outside the school matter even more than what goes on inside it" [8]. In other words, school reflects social and political ideals of a particular nation, and the main value of the comparative approach should be analysis of the causes which produced whole "educational machinery". Starting with the analysis of differences between national systems of education and their origins and then studying the solutions introduced might bring a more comprehensive view on education than just the interpretation of this process as a set of schoolroom procedures. This approach led to development of "internationalism", arising from appreciative understanding of other as well as one's own nation. For that reason, comparative education studies were conducted as deep, emotionless analytical works aimed at lowering the barriers of ethnocentrism and contributing to better understanding between the nations [9].

Based on the contribution made by the mentioned authors, Bereday claimed that the knowledge on other nations delivered by the comparison is a matter of not only curiosity but also necessity. First, it may be used to make conclusions from achievements and mistakes of other nations, to generate some practical clues for a particular society, which may turn out helpful in the development of their own education system. What is more, foreign education studies help a nation to become more aware of its roots and heritage, and to evaluate the educational issues from a global rather than ethnocentric point of view, at the same time being aware of diversified perspectives. Dealing with two or more cultures leads to better understanding of others and of ourselves.

\section{Bereday's comparative method in education}

For this author, the social and political circumstances of education system were the key point of interest, which he expressed in one of his best-known works entitled Comparative Method in Education (1964). In his opinion they, were the most important determinants of the school life and its development in a particular country, as they are "deeply enmeshed in a matrix of social circumstances". Therefore, "they cannot be compared without a careful accounting for a total situation" [10]. 
The central point which the research method should be focused on was development of a correct way of making comparisons, which brought comparative education close to other disciplines, within which the political systems could be compared or intercultural studies conducted. According to Bereday, the discussed field of knowledge was deeply rooted in the science of politics or geography. It was also based on methods adopted in philosophy, psychology, literature or statistics. Its proper task was, as Bereday stated it, to combine the subject of interest in the humanities and social sciences with the geographical perspective of education. For this reason, comparative education cannot be treated simply as a history of education or educational thought, but rather as a "current history of education", thus referring to phenomena which occur dynamically while observed and participated in [11].

As far as this domain was located within the social sciences, it could be a part of anthropology, sociology or economics of education, but it could not be identified with any particular discipline. It should be treated as a combination of certain or all elements. Therefore, comparative education was a "political geography of schools" and its role was to search knowledge about various variants of educational practice in various societies, leaning on research methods used by other above-mentioned disciplines.

As for the "technical" side of research, Bereday saw two stages here. The first included a descriptive study of a specific region (area studies), a kind of "educational geography" within which specific data and information were collected. While the second had its clear explanatory dimension and was also referred to as a social analysis - this is when the scholar applied methods and tools employed in other fields of social sciences in order to interpret the previously obtained data. Mutual confrontation of these data was the starting point for comparisons in the international dimension.

Bereday stressed that the area studies demanded not only knowledge of the foreign language or living abroad, but also extreme watchfulness in the observation process. First of all, the researcher had to be aware and at the same time disciplined enough to control any cultural stereotypes and personal prejudices that he might manifest in everyday life. It is worth noting that a demand of scientific objectivity is somehow interfered with in the very decision on the topic of research, as it is governed by a personal interest and an individual attitude displayed by the scholar who considers a particular problem as worth of his or her analysis.

Referring to his temporal stay in the examined territory, Bereday - following Edmund King - suggested that this solution may interfere with the condition of objectivity, as it could induce a sense of alienation, excessive distance, and thus lack of understanding of cultural or social nuances. The opposite situation is also possible, namely the far-reaching degree of integration with the analyzed environment, the sense of identification with the region (country) or establishing social or friendly ties with the local community [12].

Bereday suggested the use of documents and materials available without visiting a specific place as an alternative or a supplementing source of information. Establishing some contact with entities from a given region or country, institutions as well as individuals, for example foreign teachers seemed to be the most natural way. Bereday added the need for the researcher's constant participation in the examined country's culture. This can be achieved through various media: listening to the radio, reading the press, as well as accessing some photographic materials and cinematography which are channels enabling mediated, but also systematic contact with political, social and cultural conditions of a given country or region. They are indispensable elements providing a cultural context for any implemented educational projects, reforms or priorities that are formulated in the field of education and training.

For obvious reasons, this type of research activity, both covering temporary presence in the studied area, and focusing on indirect access to important information and data from the research point of view, would be impossible without at least elementary knowledge of the 
language. Translator's assistance could turn out significant here, however, this was the researcher's linguistic competence what was of crucial importance. Language skills sharpened the perception of certain phenomena, seemingly irrelevant, which might be consequently important to explain certain phenomena. In addition, as Bereday pointed it out, only the knowledge of the language gives the researcher a chance to "fuse" with the culture he or she examined.

Bereday also referred in detail to the interpretation of data obtained in the process of observation. For this purpose, the knowledge in several areas that could be considered as auxiliary in relation to education, such as history, sociology or economics was essential. What is more, all fields of social sciences and humanities should be treated as a kind of intellectual background, broadening horizons and research perspectives in the area of education. In this context, Bereday again formulated the thesis that adopting the political science (political geography) as a superior discipline would provide the researchers with more courage in discovering the links between educational processes and diverse social and cultural issues. Hence, reaching for knowledge in the field of literature, demography or religion studies could ensure some significant explanatory tools.

Gathering relevant data on education in a given area or areas (regions or countries), regardless of whether the description will be expanded by an attempt to explain the regularities to the broadest extent or not, allow to generate the definitions of comparative research in education. At this stage, it is necessary to switch to real comparative studies. The comparison, however, cannot be based on the articulation of statements about the observed facts. In order to be able to talk about the comparison of the studied phenomena, it is necessary to juxtapose them. It demanded enumeration of education practices in selected countries to trace an issue which was interesting for the researcher. The next step was to review the data under the leading phenomenon and to sum them up in the hypothesis stating the essence of the comparison to be undertaken. As Bereday put it: "Even the most superficial comparison opens the eyes of the student to the truly broadening vistas. This extra dimension to the total thinking processes is the most substantial contribution that comparative studies in general have to offer" [13].

\section{Soviet school}

Besides the methodological aspects of comparative education studies, Bereday - as an author and editor - examined some selected education systems, placing them in a wide socio-political context, according to his view on the discipline. One of the countries and systems of his interest was the Soviet Union.

In Modernization and Diversity in Soviet Education with Special Reference to Nationality Groups this country was described as a Third New Nation, following The United States and Japan in its development as a modern political and economic power [14].

Bereday started with general characteristic of the Soviet school development, determined by pre-revolutionary history and Tsarist educational policy, particularly ineffective in increasing literacy level of the society. In the early years of Soviet regime, the main goal was to "train all the people to build the socialist and industrial state that would devote itself in time to the increased well-being of the population as a whole" [15]. Among the key determinants of the rise of Soviet power, Bereday indicated education and modernization, having pointed out the correlation between them and the Soviet political and economic development. Although it was hardly possible to track the result of such an interaction precisely, some aspects of this process could be documented. Successes in the field of military-technological achievements, such as rocket technology or launching of satellites attracted the world's attention causing the technical education in the USSR to become a topic of discussion abroad [16]. 
Despite the Soviet government's attempts to expand the educational opportunities for everyone, there were certain difficulties that occurred. This situation was partially determined by the Soviet social specificity and diversity which was forced by the federal system. As a consequence, heterogeneity of nations, languages, religions followed by different aspirations, needs and demands of particular groups, shaped the Soviet educational reforms and practice. Taking into account the presence of such various nations and cultures as Ukrainians, Balts as well as people of Asian and Caucasian origin, some difficulties in performing consistent educational policy could be easily observed.

The main goal of the educational efforts undertaken by the Soviet authorities was its contribution to modernization of the country, which included development of vocational education and so-called polytechnization of education [17]. It also demanded assimilation under the leadership of the politically dominant Russian ethnic group. This assimilation was forced by the Russian language of instruction and Russian textbooks at primary and secondary level of education. It was perceived as a vital condition of professional and academic education of an individual. Although the demand of free and open access to education was one of the core elements of a communist party's program, this access was significantly limited: "The official formula of Soviet administration is democratic centralization", which ensured the strict uniformity of school organization and policy, typical for the communist system [18]. For that reason, Bereday called the Soviet system as the one aimed at diversity within unity - contrary to the American system of education [19].

\section{American-Japanese program}

The education in the United States and Japan was a topic of Bereday's American Education through Japanese Eyes written together with Shigeo Masui from the National Institute for Educational Research in Tokyo. In this publication, Bereday's fascination with Japanese culture and civilization can be easily noticed. He focused his attention on the postwar modernization of the country and the society especially in terms of transformations observed in the young generation lifestyle. The school had a key role to play in those processes [20].

The program was held between 1964-1968. It is worth noting that the initiative was undertaken by Japanese businessmen, as they perceived it as a part of social responsibility of business. The idea was supported politically by Robert Kennedy, who visited Japan and whose involvement in the project resulted in financial support from the Ford Foundation. The Program was supervised by Columbia University, represented by G. Bereday, and Kyushiu University. The main idea of the project was to invite Japanese teachers to the United States. The number of participants during the whole period of four years was 150 , and each of them was supposed to spend two months in the US. They lived with selected American families and they visited schools. No particular aim was specified - the only condition was to record the teachers' observations and to disseminate this content in Japan. As a result, there were hundreds of papers, reports and essays published in Japan, triggering high interest among the educational authorities, other teachers and the public opinion in general [21].

The purpose of this idea was not only to acquaint the guests with American school life, but first of all to overcome the stereotypical views or even mutual hostility existing in both societies due to the historical and political reasons. It was a fruitful experience for both sides: on the one hand Japanese teachers had an opportunity to confront themselves with a decentralized model of school administration which was they were completely unfamiliar with. The Americans on the other hand gained an opportunity to "face the others", not only on the professional ground at schools visited by those Japanese teachers, but also on private terms, as the hosts of guests from Japan. "Many participants expressed that the Project not 
only added new knowledge and information on American things, but also changed their views and images of America completely" [22].

One of the most evident differences in American and Japanese school administration was decentralization vs. centralization of the system. Japanese teachers were aware of this American specificity, as they had participated in seminars and lectures on American education before their visit to the US. However, when confronted with it, they were shocked and bewildered, but also able to notice some positive output of this solution. Moreover, they were fascinated by the degree of American teachers' participation in the decision-making process concerning the school life. They were impressed by the plurality of relationships among various groups involved in the process of education, but they were also concerned about the lack of "formal ritualistic rigidities", what was caused by Japanese customs and tradition [23].

The teaching content also posed an interesting area of differences between both countries. For example, this was the case with the field of moral education, one of the core elements within Japanese school curriculum, apart from physical and intellectual education, in fact one of three major areas of the development of the youth. In the American school this issue occurred to a quite limited extent, as it was diffused in various subjects, left to the parents or omitted for the purpose of educating individuals who act independently and are not attached to a single specific way of behavior. From that point of view, according to the Bereday's way of perceiving the role of comparative studies not only in the field education, a significant element is to provide knowledge which allows the students to see a "true face of foreign people and to show their own faces reflected in foreigners' eyes" [24].

Apart from Japanese criticism towards selected American educational practices, the program helped to overcome the national bias of both nationalities. What appeared one of the most interesting results of the Japanese visit to the US was the noticeable homogenization of views concerning not only the school life - there were some observations about American education which became postulates for Japanese education. This process had its manifestation also in the attitude towards current political issues of that time, namely Vietnam war, atomic stockpiles or the Okinawa case. The Japanese teachers discovered that plenty of Americans shared their points of view which had a calming effect and opened the way for intellectual homogenization. It was a determining step towards "international community of teachers", as Bereday and Masui concluded [25].

\section{Academic education}

Another topic of Bereday's interest was the issue of mass education, including university level, in relation to the education of professionals. In his book entitled Universities for All, he asked a provocative question of whether a department for engineers should exist side by side with a department for plumbers, "both instructed in their skill with the addition of a healthy dose of Plato". Anticipating the controversy which might arise, Bereday claimed that in the world where $60 \%$ of population was still illiterate, even one-year universal schooling was an extremely ambitious goal, taking into account that even the access to the compulsory education was limited in the industrialized countries of that time [26].

The ideal, as Bereday described it, would have been if all human beings were admitted to graduation without exclusion. Nevertheless, it was hard to imagine that accessibility of higher education on a mass level would ever come true. Although Universities were described as a bastion of cultural stability, their role raised (and still does today) some controversies. There was a sort of clash between academic activities, namely research and teaching, as it was extremely difficult to combine those two areas. Another field of academic activity and responsibility is the public service, particularly in terms of shaping the public opinion. Modernization of social life and industrialization of economy were the 
main reasons why the university was not able to perform these complex roles effectively. A university was rather expected to meet the aims of a modern industrialized society, which involved educating professionals of various fields. As a consequence, scholars became the teaching staff rather than the contemplative academicians. Therefore, a major thrust of that time was in "the direction of the university as a school" [27].

An answer for the public demand on access to universities could have been be a sort of a union between intellectual elitism and mass opportunity, a popular model emerging in European educational institutions, which Bereday called as hybridized. The weakness of this concept was a division between university and non-university institutions which caused some tensions between "first-rate and second-rate minds" which might lead to destruction of the academy" [28].

In this context, Bereday underlined the fact that higher education should not only concentrate on young adults, but it should also include education "from cradle to grave lifelong education". Many governments, partially inspired by egalitarian ideas and social equality, became more aware of people's expectations and ambitions, as well as the role of the educated population in the national growth. Hence, such solutions as establishing higher education institutions in rural areas, developing a network of student dormitories, providing work-study programs and organizing some financial assistance for the students, shaped the frames for democratization of higher education. Although the situation of women and minorities was improved, there still was a significant gap between particular groups, depending on their socio-economic status as well as customs and traditions existing in a given nation or region [29].

For that reason, Bereday's aim, from the comparative education point of view, was to create a theory for the mass higher education. The arguments Bereday adopted for his concept, grasped the idea of to use the human potential. He claimed that open admission did not mean a lower quality, and the high standards would have not been damaged if they were more flexible and less pedantic. This situation might lead to effective use of the people's ambitions. Another argument for mass higher education was an educational upgrade of all professions, as according to Bereday, there was no such a thing as overproduction of people with high qualifications. Besides, mass education did not mean egalitarian but rather an open school: "The curriculum must give most to those who have the least in order to increase the academic comprehension of the mass rather than simply reinforce existing disparities" [30].

The conclusive argument supporting such a solution, in spite of potential controversies or even resistance of conservative academic institutions, was the fact that: "The many new opportunities for higher studies help to create resourceful, well-motivated and critical population. Higher education is correctly thought to be a precondition of good democracy" [31].

\section{Juvenile law}

Bereday focused his research also on the activities in the field of juvenile law systems, in the comparative view, taking into account the competent institutions and applicable provisions existing in the US, the USSR, China, Sweden, Japan and France. What is significant is that after 20 years as a university professor, he decided to enroll as a first-year student at Columbia Law School for that purpose [32].

Juvenile law was defined as all legal matters concerning minors, to avoid isolating legal issues of this field from one another [33]. It is important to mention that the range of the topics was highly extensive, from defending the rights to property of unborn as a descendant, through suing for malparenting, right to bilingual education, to trials before the court. According to this variety of issues, the juvenile law might be divided into five 
sections: 1) law of life, 2) law of infants, 3) civic law, 4) school law, 5) juvenile justice (court law) [34].

The first section addressed the issues concerning prenatal life, related to abortion. Bereday referred to the 19th century views and the catholic standpoint assuming it is a manslaughter and underlining the rights of adults, namely of mothers who cannot not be described as instruments of ensuring human race's future and their right to the privacy of their bodies which prevailed. The juvenile law was therefore reflected in the rule that life of an adult was still superior to the life of a being about to be born. Further issues discussed in this section were: contraceptives, sterilization [35]. In another manuscript, Bereday introduced a classification, where those three elements were included in the "Prevention" category. There was also the "Protection" category added, including artificial insemination (previously under the "Prevention" category), surrogate mothers and prenatal torts [36].

The second section, law of infants, concerned the rights of infants that started with the time of their birth. They regulated the parents' position in their children' lives as well as the state's position and the instruments its institutions might use in case of any mistreatment of the children. This area comprised of such problems as the best interest of the child in terms of custody, contacting natural parents, children's financial support, or the so-called childsnatching. Another topic was illegitimacy of children and their unequal treatment as a consequence of such a distinction. Bereday referred to the problem of adoption, foster families, the domicile arrangements in case of the parents' divorce.

Civic law put forward the question in what extent the minors should have been treated as adults. It concerned various rights and duties in connection with parental guidance responsible for the general control of their children. For example: issuing driving license to juveniles, employment of minors, medical consent, inheritance and administration of their own property, voting rights.

School law addressed the issues of the state-church relationship and the secular vs. religious training, students' freedom to express their opinion, search and seizure, suspension and expulsion. Other topics are censorship of school newspapers, sexual education, bilingual education of immigrant children, equal educational opportunities for disabled children.

Juvenile justice was the most noticeable area of juvenile law, commonly recognized by the public opinion, and those terms were often used interchangeably. The former, however, applies to children in front of the court, as victims and as offenders. Bereday mentioned neglected and abused children in the first group. Several groups depending on the sort of crime they committed may be distinguished among the offenders. Regardless of whether they are tried in front of a family, a juvenile or an adult court, they had the right to be heard, and in the case of the adult court, the right to a counsel, the trial by jury and to plea bargaining, as well as they were placed in separate parts of penitentiaries if incarcerated [37].

Among the reasons for examination of this topic, Bereday mentioned that it is a history and civilization demand, as the equal protection of various groups was developed within the course of years, including social classes, race and ethnic minorities. The remained category to protect would be therefore only the one distinguished by the age, and the recognition of the importance of law affecting minors is getting public attention [38]. From this point of view, it was rather an innovative attitude, more typical for the present decades, when awareness of the children's rights promotion and protection has become widely discussed worldwide.

As some of Bereday's and his colleagues works above-mentioned have never been published, it can be assumed that they were prepared for the didactics purposes, as the materials for the lectures or seminars addressed to students. Gottesman Library at Teachers College of Columbia University has also a draft of article entitled An Introduction to 
Juvenile Law and Its Bibliography in its archive. The research was supported by a grant from the Richard Lounsberry Foundation, a draft includes names of the assistants who cooperated with Bereday in its preparation, but there is no date when it was written. The article includes references to books and papers published in 1981 and earlier, therefore on it may be assumed that Bereday was not able to publish it before his death in 1983. It may be the reason why there are only few Bereday's publications concerning the topic are available.

\section{Conclusion - Bereday's impact today}

Although Bereday's activity fell on the second half of 20th century, his influence on contemporary shape of science of education is indisputable. Taking into account his contribution to research on methodology, some authors [39] ascribe him with the four steps of comparison model (description - interpretation - juxtaposition - comparison: "First description, the systematic collection of pedagogical information in one country, then interpretation, the analysis in terms of social sciences, then juxtaposition, a simultaneous review of several systems to determine the framework in which to compare them, and finally comparison, first of select problems and then of the total relevance of education in several countries - these four steps point the way to the future for comparative education" [40].

However, other authors attribute this invention to Franz Hilker, explaining that he could be possibly forgotten, as his works were published in German and he was not able to become popular in English-speaking community of researchers [41]. Bereday was familiar with Hilker's book entitled Vergleichende Pädagogik of 1964, as he in his letter to Hilker clearly referred to this matter, informing Hilker that the book was going to be reviewed for "Comparative Education Review" by William Brickman. Bereday was a bit critical towards the concept - he was appreciative but he thought that "it deals with mechanics rather than the content of analysis" [42]. Therefore, it is quite obvious that both authors knew each other's works, discussed them and treated them as an inspiration for their further research activity. Taking into account the concept of four steps of the comparison model, it is worth underlining that while discussing the two main 'purposes of comparison' - interpretive or causal-analytic - Bereday's approach could be described as the interpretive one [43]. Despite of the limitations brought by the four steps model, it has led to new and different methodologies today [44].

Moreover, Bereday and Hilker were leading figures in the beginnings of academic associations in comparative education. Bereday's name should be mentioned in a context of the origins of the US-based Comparative Education Society (CES) founded in 1956, which was renamed as the Comparative and International Education Society (CIES) in 1969. The idea for an international conference in London in May 1961 led to the founding of the Comparative Education Society in Europe (CESE). In 1957, Bereday became the first editor of the "Comparative Education Review", the society journal of the US-based CES (later CIES), the academic journal that still exists today.

William Brickman, the president of the Comparative Education Society, in his editorial note in the first issue explained the aims of this publication: "It aspires to be a clearing house of basic data and resources for the effective teaching of comparative education at the colleges and universities" [45]. In the eulogy after Bereday's death, Phillip Altbach highlighted his "commitment to reflect a broader parameter of the field rather than to shape a journal in the image of one scholarly approach or ideology" [46].

In 1980, the first award committee was formed to review articles published in the "Comparative Education Review". The mandate was to review all the articles published in the preceding year in terms of their significance for shaping the field, analytic merit, policy 
implications, concern for theoretical constructs and implications for future research. In 1989, the CIES Awards Committee formally named the award as: The George Bereday Annual Best CER Article Award. The award was first granted in 1981 and has been granted every year since then [47]. In 2017, the award was presented to Francine Menashy for the article entitled The Limits of Multistakeholder Governance: The Case of the Global Partnership for Education and Private Schooling".

Taking into account all scientific and academic activities that George Z. F. Bereday performed, a wide range of his interests, including not only methodological issues in educational research, but their application in his works concerning various topics he examined can be noticed. William Brickman described him as an extraordinarily talented and gifted personality: "Professor Bereday represented a rare blend of the classical and the modern, of Eastern and Western European education and scholarship, and of the Occidental and Oriental cultures," and that he "exhibited endless evidence of humanism toward other cultures and humanitarianism toward persons of all ethnic, racial, and national backgrounds" [48].

\section{References}

1. G. Z. F. Bereday, Vita, Gottesman Libraries, Teachers College, Columbia University NY (1978, May)

2. Professor George Bereday, Comparative Education, 20, 1, p. 5 (1984)

3. D. Coldrin, Interview with $d r$ Bereday, Your School Report Today, Columbus $\mathrm{OH}$ (1973, August)

4. G. Z. F. Bereday Dead; Educator, Author and Editor, The New York Times (1983, October 26).

5. E. H. Epstein, Is Marc-Antoine Jullien de Paris the 'father' of comparative education?, Compare: A Journal of Comparative and International Education, 47, 3, doi: 10.1080/03057925.2016.1254542, p. 317 (2017).

6. G. Z. F. Bereday, Comparative Method in Education, New York NY: Holt, Rinehart and Winston Inc., pp. 7-10 (1964)

7. Ibid., p. 8 .

8. I. L. Kandel Comparative Education, Cambridge MA: The Riverside Press, Introduction, xix (1933)

9. Ibid., Introduction $\mathrm{xxv}$

10. G. Z. F. Bereday, op. cit., Preface, ix (1964)

11. Ibid., Preface, $x$

12. E. King, Students, Teachers, and Researchers in Comparative Education, Comparative Education Review, 3, 1, p. 34 (1959)

13. G. Z. F. Bereday, op. cit., p. 23 (1964).

14. G. Z. F. Bereday, J. Pennar, I. Bakalo, Modernization and Diversity in Soviet Education, New York NY: Praeger Publishers, Preface, v (1971)

15. Ibid., p. 31.

16. R. Karça, A General View of Soviet Education. In G. Z. F. Bereday, J. Pennar (eds.), The Politics of Soviet Union, New York NY: Frederick A. Praeger, p. 3 (1959)

17. G. Z. F. Bereday, American and Soviet Scientific Potential, Social Problems, 4, 3, p. 213 (1957) 
18. G. Z. F. Bereday, Changes in Soviet Educational Administration, School and Society, 86 (2124), p. 38 (1958, January 18)

19. G. Z. F. Bereday, J. Pennar, I. Bakalo, op. cit., p. 341 (1971)

20. G. Z. F. Bereday, S. Masui, American Education through Japanese Eyes, Honolulu: The University Press of Hawaii, Preface, vii (1973)

21. T. Kobayashi, On the Japanese-American Teachers Project: A Report to the Director, Gottesman Libraries, Teachers College, Columbia University NY, pp. 1-12 (1964, November)

22. Ibid., p. 10.

23. G. Z. F. Bereday, S. Masui, op. cit., pp. 3-23 (1973)

24. G. Z. F Bereday, op. cit., p. 6 (1964)

25. G. Z. F. Bereday, S. Masui, op. cit., p. 227 (1973).

26. G. Z. F. Bereday, Universities for All, San Francisco CA: Jossey-Bass Publishers, pp. 1-2.(1973)

27. Ibid., p. 14

28. Ibid., p. 16

29. 29.G. Z. F. Bereday, Democratization of Higher Education, Educational Information and Documentation. Bulletin of International Bureau of Education, 53, 210, ParisGeneva: UNESCO, pp. 14-16 (1979),

30. G. Z. F. Bereday, op. cit., pp. 139-145 (1973)

31. G. Z. F. Bereday, op. cit., p. 16 (1979)

32. G. Z. F. Bereday, First Semester at Law School, Intellect. Law\&Justice, pp. 460-463 (1975, April)

33. G. Z. F. Bereday, The General Parameters of Juvenile Law, Hawaii Bar Journal, 17, 2, pp. 87-103(1982)

34. G. Z. F. Bereday, B. L, Morton, R. Galbraith, Comparative Juvenile Law. Outline of Research (manuscript), Gottesman Libraries, Teachers College, Columbia University NY, p. 3

35. Ibid., p. 13

36. G. Z. F. Bereday., American Juvenile Law. Cases and Materials (manuscript), Gottesman Libraries, Teachers College, Columbia University NY

37. G. Z. F. Bereday, Juvenile Deliquents, the Deprived and the Acculturation Process. In Vergleichende Erziehungswissenchaft, U. Baumann, V. Lenhart, A. Zimmermann (eds.), Wiesbaden: Akademische Verlagsgesellschaft, p. 255 (1981)

38. G. Z. F. Bereday, The Basic Premises of Juvenile Law and an Introductory Reading (manuscript), Gottesman Libraries, Teachers College, Columbia University NY

39. M. Manzon, Comparing Places. In Comparative Education Research. Approaches and Methods, M. Bray, B. Adamson, M. Mason (eds.), Hong Kong-Dordrecht: Springer, p. 99.(2007)

40. G. Z. F. Bereday, op. cit, pp. 27-28 (1964)

41. Ch. Adick, Bereday and Hilker: Origins of the 'Four Steps of Comparison' Model, Comparative Education, 54, 1, doi: 10.1080/03050068.2017.1396088, p. 36 (2018)

42. G. Z. F. Bereday, Letter to Franz Hilker, Gottesman Libraries, Teachers College, Columbia University NY (1962, October 31)

43. M. Manzon, op. cit, p. 99 
44. Ch. Adick, op. cit, p. 44

45. W. Brickman , A New Journal in Comparative Education, Comparative Education Review, 1, 1, p. 1

46. J. Cossa, Shaping the Intellectual Landscape. In Crafting a Global Field. Six Decades of the Comparative and International Education Society, E. H. Epstein (ed.), Hong Kong: Springer, p. 132 (2016)

47. Comparative and International Education Society George Bereday Award, https://www.cies.us/general/custom.asp?page=BeredayAward (2018), Accessed: 27.06.2018.

48. Comparative Education Review, George Z. F. Bereday Award for 2015, 60, 2, pp. 420421. (2016, May) 